\title{
Ximena Baraibar
}

Departamento de Trabajo Social. Facultad de Ciencias Sociales.

Universidad de la República. Uruguay

xbaraibar@gmail.com

\section{EL PROBLEMA DE LA CONSTRUCCION DEL PROBLEMA: UNA MIRADA AL NUEVO GOBIERNO URUGUAYO A PARTIR DEL COVID-19}

\begin{abstract}
Resumen: En Uruguay, el 13 de marzo fue declarada la emergencia sanitaria por COVID-19, siendo atendida por el gobierno asumido el 1 de ese mes. Este artículo analiza la configuración del problema en relación a las poblaciones con bajos o nulos ingresos. Esto es relevante, en tanto impactará en las respuestas implementadas y considerando es expresión de la mirada del gobierno, del acceso a la protección y bienestar social. Se concluye que el COVID-19 es considerado un problema profundo pero breve, con dimensiones casi exclusivamente sanitarias y económicas, por fuera de la desigualdad y asociadas las necesidades a expresiones mínimas.
\end{abstract}

Palabras clave: Uruguay, protección social, pobreza, desigualdad

The problem of the construction of the problem: a look at the Uruguayan new government from COVID-19

\begin{abstract}
On March 13, the Uruguayan government declared a public health emergency due to COVID-19, and was handled by the government that took office the ist of that month. This article analyzes the configuration of the problem in relation to populations with low or no income. This is relevant, as it will have an impact on the implemented responses and has to be considered as an expression of the government's view of access to protection and social welfare. It is concluded that COVID-19 is considered a deep but brief problem, with almost exclusively health and economic dimensions, outside of inequality and associating needs with minimal expressions.
\end{abstract}

Keywords: Uruguay, social protection, poverty, inequality 


\section{Introducción}

El COVID-19, en Uruguay, como asunto de debate público y a atender por el gobierno y la ciudadanía, llegó el 13 de marzo. Ese día, el Presidente Luis Lacalle, en conferencia de prensa anunciaba los primeros cuatro casos positivos y con ellos, la emergencia sanitaria. Una de las singularidades en ese país, refiere a la simultaneidad entre el nuevo virus y el nuevo gobierno, el que asumiera el 1 de ese mes y 15 días antes lo hacía el nuevo Parlamento, que funcionará los próximos cinco años. Esto suponía también una rotación del partido a cargo del gobierno y daba por terminado tres períodos consecutivos (15 años) de gobierno en manos del Frente Amplio.

El nuevo Presidente resultó electo en la segunda vuelta electoral en noviembre de 2019. Producto de un acuerdo entre cuatro partidos de derecha y centro derecha, la fórmula presidencial integrada por Luis Lacalle y Beatriz Argimón, obtuvo el $48.8 \%$ del total de los votos emitidos ${ }^{1}$. Ese porcentaje, parala alternativa -la fórmula encabezada por Daniel Martínez y Graciela Villar-, fue del 47.3\% (Corte Electoral, 2019).

A partir de la emergencia sanitaria, el gobierno instala una lógica de anuncios permanentes y extendidos, que son amplificados por la enorme cobertura que realizan los medios masivos de comunicación y fundamentalmente, los canales privados de televisión. Se desarrollan una gran cantidad de conferencias de prensa, además de comunicados de Presidencia de la República y del Sistema Nacional de Emergencias (SINAE) que es quien reporta los casos afectados por el virus. Estos reportes, así como las conferencias de prensa ocurren durante el desarrollo de los informativos, que además extienden sus horarios. A esto se suman diversos programas, durante variados horarios y también centrados en estos asuntos, que, hasta fines de abril, transcurren con sectores importantes de la población aislados en sus hogares. Se instala la imagen de un gobierno 'que se hace cargo' y de cara a la ciudadanía y de manera transparente.

A partir de la nueva realidad surgida el 13 de marzo, el gobierno anuncia un conjunto de medidas, referidas tanto a la movilidad dentro y fuera del país, la educación, los trabajadores formales, los espectáculos públicos y las actividades deportivas, entre otras. Asimismo, se ponen en marcha acciones concretas de atención a los efectos sobre el

\begin{abstract}
${ }^{1}$ En la primera vuelta electoral, en octubre de 2019, el Frente Amplio fue el partido más votado con el 39\% de los votos. En segundo lugar, el Partido Nacional obtuvo el $28.6 \%$ de los votos. Entre octubre y noviembre, se conforma la denominada 'coalición multicolor'. Al Partido Nacional se suma el Partido Colorado (con el 12.3\% de los votos), ambos partidos históricos. Otro sector relevante es Cabildo Abierto, un partido creado a inicios del 2019 , obteniendo el $11 \%$ de votos y liderado por el ex Comandante en Jefe de las Fuerzas Armadas, Guido Manini Ríos. También integran esa coalición el Partido Independiente y el Partido de la Gente, ambos con muy escasa relevancia electoral. El primero obtuvo el $0.8 \%$ de los votos y el segundo, el 1\%. Salvo en el último caso, los restantes partidos se encuentran ocupando distintos cargos en el gobierno nacional (Corte Electoral, 2019).
\end{abstract}


trabajo informal y los ingresos y en particular, la pobreza.

Las políticas públicas y más concretamente las políticas sociales existen procurando atender algo, que -de manera más o menos desarrollada-, se configura como problemático. No habrá respuesta sobre aquello que, de alguna forma, no es entendido como problema y, por tanto, un asunto a atender. En tanto la construcción de las respuestas tiene que ver con la que se realiza del problema, se vuelve relevante procurar entender que es lo que se dice sobre este, que características se le atribuyen y como se lo explica.

Este artículo tiene como objetivo analizar la manera en que el nuevo gobierno, a partir del COVID - 19, construye como problema a la pobreza, la informalidad y la falta de ingresos. Para esto toma como base la información oficial existente fundamentalmente en los sitios web de Presidencia y del Ministerio de Desarrollo Social (MIDES) y la comunicación realizada por el gobierno e integrantes del Partido Nacional.

Ese análisis se realiza ubicándolo en el contexto más general de lineamentos políticos promovidos por el nuevo gobierno y es considerando relevante por dos asuntos fundamentales. De manera contraria a lo señalado por el Presidente, se parte de valorar que gobernar supone siempre decisiones políticas, expresadas en lo que se decide y resuelve, así como en lo que no se dice y aquello que se opta por dejar hacer. Pero, además, dado que se entiende que la forma de configurar el problema en esta crisis es indicativa de la manera en que el gobierno visualiza los espacios y mecanismos a través de los cuales las personas accederían al bienestar y la protección social. Ante la coincidencia en el inicio del coronavirus y el nuevo gobierno, mirar las valoraciones y construcciones sobre el primero, supone tener indicios importantes de las apuestas del segundo.

Se concluye que el COVID-19, ingresa como problema, perolo hace desde cuatro aspectos que resultan problemáticos: es tomado como un problema con dimensiones casi exclusivamente sanitarias y económicas y como un asunto que -salvo en lo que refiere a la edad- parecería afectar a todas las personas por igual. Esto no supone no reconocer que hay poblaciones en situaciones más complicadas, pero esa valoración -y esto configura el tercer aspecto-, se hace por fuera de toda referencia a la desigualdad y asociada casi exclusivamente a expresiones mínimas, teniendo centralidad 'el plato de comida'. Finalmente, es considerado un problema 
profundo, pero breve. Esto se da en un contexto general donde se manifiestan sospechas sobre las cifras oficiales de pobreza e informalidad, se opone la política a la gestión de gobierno y donde las claras preocupaciones de este, estuvieron -antes de asumir y luego de hacerlo-, colocadas en la llamada Ley de Urgente Consideración (LUC).

Esa manera de configurar el problema, tiene expresiones rápidas y concretas en las respuestas públicas a la pobreza y la informalidad. Estas -aunque reiteradamente anunciadas- se caracterizan por ser residuales y desajustadas a la realidad a atender, son por poco tiempo y con apuestas a las expresiones de la sociedad civil (fundamentalmente ollas populares y donaciones básicamente de canastas de alimentos). Esto, en un escenario que tiene y tendrá dificultades para incorporar y de manera formalizada a sectores importantes al mercado de trabajo, permiten suponer que lo que viene en el futuro uruguayo, será la desprotección de amplios sectores de la sociedad, el crecimiento de la pobreza y la profundización de la desigualdad.

Para alcanzar el propósito mencionado, el artículo se organiza en tres partes. La primera se centra en asuntos que hacen a la construcción del problema en la política social. Luego se plantea la manera en que el COVID-19 se configura en problema en relación a la pobreza, la informalidad y la ausencia o bajos ingresos. Esto se realiza ubicándolo dentro de la orientación más amplia sobre la manera en que, como problema es colocado en el Uruguay, por parte del nuevo gobierno. Finalmente, el artículo se cierra con una síntesis y problematización de lo anunciado.

\section{La construcción del problema, la política social y los regímenes de bienestar}

La política social es comprendida como

(...) aquellas intervenciones públicas que regulan las formas en que la población se reproduce y socializa (sobrevive físicamente y se inserta en el mundo del trabajo y en el espacio sociocultural del Estadonación); y protegen a la población de situaciones que ponen en riesgo estos procesos" (Solando, Daniela y Andrenacci, Luciano, 2005, p.32).

Así definida, consideran además que se expresa en tres modalidades analíticamente diferenciables, aunque 
generalmente combinadas: la política del trabajo, la de servicios universales y la asistencial.

Como fuera indicado, la política pública y más en concreto, la política social existe para atender a algo que de una manera más o menos desarrollada y fundamentada, se configura como problema y/o una realidad a mejorar. Esto hace que visualizar la forma en que se plantea un problema, sea fundamental en tanto tendrá impactos en las decisiones que tomen los gobiernos $y$, por tanto, en las condiciones de vida de las personas y la sociedad en su conjunto. Entienden Malena Hopp y Eliana Lijterman (2018) que examinar los discursos sociales que conforman el sentido común acerca de los principios que sostienen o critican los regímenes de política social y dan fundamento a distintos modelos de Estado, adquiere siempre especial relevancia.

Lo señalado supone un primer asunto importante. Tal como señala Estela Grassi (2008) la aflicción de un grupo social, no es en sí mismo un problema social, sino que supone su constitución como tal y es dependiente de los procesos con los que se lo nomina, describe y especifica. Agrega que la política social no encuentra sin más un sujeto preconstituido, sino que, en la identificación del destinatario, lo constituye. Aún cuando los sujetos pre existen a la política social, esta participa del poder de su constitución, sean como personas asistidas, trabajadoras, pobres, o como ciudadanía (Grassi, Estela, 2013).

Considera la autora además que un problema no se define de manera aislada, sino como parte de una red de problemas y "Por lo tanto, la disputa por su definición es también por la determinación de las causas, por la atribución de responsabilidades por su formación, por la determinación de ámbitos de competencia en las soluciones y por los alcances de la voluntad política de intervención" (Grassi, Estela, 2006, p.22).

Esto lleva al segundo aspecto y es que en la política social se juega siempre una construcción política, lo que supone cuestionar su reducción a simples asuntos técnicos. La expresión que porta la política social es objeto de disputa y remite a una forma de comprensión de la cuestión social. De acuerdo a Ernesto Crespo y Amparo Serrano (2013) una función fundamental de una política es construir un sentido común acerca del asunto en cuestión, que servirá como fundamento de la intervención. En similar sentido, 
agrega Estela Grassi (2006) que los programas de los diversos sectores de la política social, no pueden ser comprendidos como simples asuntos de gestión o respuesta a problemas predefinidos. Esos programas -que operan como solución de problemas sociales-, expresan, contienen y participan en la producción de esos argumentos y en sus disputas.

La política social define que personas son nominadas como merecedoras de atención y en que radica dicho merecimiento. A través de la misma:

... se expresa y se produce, un modo de realización de la reproducción que supone criterios de: i) mayor o menor socialización en lo relativo a la satisfacción de las necesidades; ii) mayor o menor cantidad y calidad de los satisfactores. Además, estas cuantías expresan y producen distinciones sociales y por lo tanto por ellas se contribuye a construir sujetos provistos de diferentes atributos. En síntesis, las políticas sociales conllevan un concepto de necesidad implícito, del que depende la determinación de aquellas a cuya satisfacción se orientarán de manera explícita las intervenciones en política social, y a quienes les son atribuidas y reconocidas (Grassi, Estela, 2008, p. 47).

En similar sentido, Claudia Danani (2009) considera que el desarrollo de la política social supone la definición de las personas a las que se dirige, los objetos y medios legítimos de satisfacción de las necesidades y agrega que:

(...) a través de la política social, se expresan y construyen, simultáneamente, los modos de vida y las condiciones de reproducción en una sociedad; condiciones que, en sociedades de clase, son siempre diferenciales para los distintos grupos sociales. Es el saldo de la lucha social y política, la que defina los contenidos y alcances de la desigualdad resultante (Danani, Claudia, 2009, p. 36).

Esta perspectiva, también implica otro aspecto relevante y es que la simple existencia de la política social, no supone necesariamente una mejora en las condiciones de vida de aquellas y aquellos a quienes va dirigida. Esto no es una característica propia de la política social en sí misma. Tampoco constituye un atributo propio la situación contraria, esto es, que las políticas sociales empeoren las condiciones de vida. Estas pueden mejorar la vida, pero no necesariamente lo hacen (Danani, Claudia, 2008).

Agrega la autora que la política social socializa la reproducción, solo si la satisfacción de necesidades se torna 
un proceso de reconocimiento de derechos de las personas. Estas -solo en esta circunstancia-, pueden al menos parcialmente, independizarse del mercado. Esta reducción de la dependencia supone que se sustraen algunos elementos de los intercambios de mercado o se establecen límites a la completa mercantilización. Esto implica un proceso de socialización y politización de la vida, contradiciendo el principio que coloca la reproducción de la vida, como un asunto privado.

Lo indicado supone que la política social, en tanto expresa una forma de comprender la cuestión social, también lo hará sobre el nivel de responsabilidad del Estado por la reproducción y por el tipo y calidad de la satisfacción. Esto dará lugar, a los regímenes de bienestar entendidos “(...) como la forma conjunta e interdependiente en que se produce y distribuye el bienestar por parte del estado, el mercado y la familia" (Gosta Esping - Andersen, 2000, p. 52). Agrega que también puede considerarse el tercer sector, donde incluye las organizaciones voluntarias o las que actúan sin ánimo de lucro.

Dirá el autor que los países desarrollados se distinguen según la forma que tomen esos tres pilares y en esa diferenciación es central el papel del Estado, permitiendo una mayor o menor desmercantilización y desfamiliarización, con impactos en la estratificación social. El primer concepto “(...) aspira a captar el grado en el que los estados del bienestar debilitan el nexo monetario al garantizar uno derechos independientes de la participación en el mercado" (Esping Andersen, Gosta, 2000, p. 64). En una lógica similar, entiende que la desfamiliarización supone “(...) políticas que reducen la dependencia individual de la familia, que maximizan la disponibilidad de recursos económicos por parte del individuo independientemente de las reciprocidades familiares o conyugales" (Esping-Andersen, Gosta, 2000, p. 66). Esta diversa presencia y forma de esos pilares, da lugar a tres regímenes de bienestar: liberal, conservador o corporativo y socialdemócrata.

En sintonía con esta perspectiva, entiende Claudia Danani (2008) que la política social es un proceso sociopolítico, institucional, económico y cultural en el que una sociedad define los sujetos, objetos y medios legítimos de satisfacción de las necesidades. De esta manera, las instituciones estatales son la expresión político - institucional de la 
responsabilidad o desresponsabilización colectiva. También destaca que la reducción de la dependencia del mercado, es de carácter político - institucional y, por tanto, diferente de la familiarización o comunitarización de la satisfacción de las necesidades. Señala que podría visualizarse al auto abastecimiento, la auto provisión o la producción para el consumo, como prácticas de desmercantilización, en tanto no hay mercado, pero dirá que:

Sin embargo, no es así (...) se ha destacado el carácter integral de un proceso genuino de este último tipo: se trata de un movimiento de sustracción del mercado que en sí mismo constituye derechos y que socializa la reproducción de la vida. La familiarización y la comunitarización ni constituyen derechos, ni socialización de la reproducción; por el contrario, la privatizan, reenviando a la esfera familiar e individual la responsabilidad por el bienestar (Danani, Claudia, 2009, p. 39).

Suponen una forma de protección que define y asigna la responsabilidad por esta y el bienestar, a los grupos primarios, tanto a la familia como a las formas propiamente comunitarias, mediadas solamente por relaciones de proximidad. Junto a la individualización, son destacados por la autora como parte de las tendencias de la protección social de los años 90. La última es entendida como una forma de orientar las políticas sociales, que supone vincular las condiciones de vida de las personas con su situación como individuo. Agrega que la protección social se individualiza cuando el acceso, la magnitud y la calidad de los servicios a los que las distintas personas acceden depende de su situación inmediata y/o de su capacidad de pago o de su suerte (Danani, Claudia, 2008).

Individualización y comunitarización suponen un proceso de de-socialización de la reproducción, entendida como la pérdida del carácter social y colectivo de la vida. Comparten la negación -en sentido material, institucional y político-cultural- por la responsabilidad social por el bienestar. La autora no pone en duda el aporte de la comunitarización para mejorar las condiciones de vida, y, al contrario, la considera con una gran potencia para sostener la reproducción. Pero:

Lo que se plantea, en cambio, es que globalmente ambas son fuente de desigualdad, porque construyen un mundo de protecciones dependientes de 
características particulares (de individuos o de grupos), sean ellas la habilidad, la disposición de medios, y aún el azar. Esa mayor dependencia de atributos particulares implica también menores garantías para esos individuos y grupos, ya que sólo la sociedad y sus instituciones público-estatales pueden prestar garantías y ser demandadas por ellos (Danani, Claudia, 2008, p. 46).

Todo esto tendrá impactos en la igualdady desigualdad de una sociedad, en tanto ambas son un resultado institucional (Danani, 2008).

También Potyara Pereira (2008) señala que la política social es producto de la conflictiva relación entre Estado y sociedad y por tanto va a lidiar con intereses opuestos, ya que resulta de la presión simultánea de sujetos distintos. Agrega que, de la misma forma, sus impactos no producen invariablemente la mejora de las condiciones humanas, especialmente de las personas más pobres. Para que esto acontezca de alguna forma, tiene que existir un control de parcelas organizadas de la sociedad sobre acciones de los gobiernos, así como sobre demandas o imposiciones del capital, que también sean acatadas y procesadas por el Estado.

Si toda intervención del Estado es objeto de disputa política, la política asistencial -de amplio desarrollo entre fines del siglo pasado y el actual- genera particulares debates. Malena Hopp y Eliana Lijterman (2018) a partir de su análisis sobre la construcción social del merecimiento en las transferencias monetarias, observan que los requisitos y atributos exigidos a los sujetos 'dependientes' de asistencia conforman un objeto de disputa que va más allá de los requisitos formales - institucionales. Y agregan que esto está atravesado por los parámetros de valoración social, especialmente en relación al trabajo asalariado que adquiere centralidad como contexto de referencia de los debates sobre el merecimiento de las intervenciones sociales del Estado. Afirman que:

El merecimiento a la asistencia se sustenta, entonces, en "razones" en estrecha conexión con juicios de valor con pretensión de universalidad. Los contenidos de la condición de merecimiento, que legitiman (o cuestionan) las intervenciones sociales y sus destinatarios, se construyen tanto a partir de un registro institucional que define las condiciones y requisitos formales deacceso a un derechoo prestación, como de un registro no institucional -social, cultural y 
subjetivo-, vinculado a las representaciones sociales y principios de justicia (Hopp, Malena y Lijterman, Eliana, 2018, p. 143).

Compartiendo lo señalado, esto es, que es la oposición entre trabajo y pobreza la que sustenta la organización institucional entre asistencia a las personas pobres $y$ seguridad social a las y los trabajadores, vale observar que la misma no toma iguales formatos en los distintos contextos económicos, sociales y políticos y en particular, se esté o no, en una situación particularmente crítica. Fuera de una realidad como esta última, entiende Ana Arias (2012) que quienes en otro momento son consideradas y considerados víctimas de la situación social, al disminuir el desempleo y la crisis económica, pasan a ser examinados como vagos o portadores de disfunciones que los convierten en pobres. Pero, en contextos de crisis: 'La 'emergencia' provocada por la crisis económica funcionaba como una explicación de la pobreza externa a los sujetos y justificaba la intervención sobre la misma de manera directa” (Arias, Ana, 2012, p. 149)

Todo lo mencionado indica que no alcanza con visualizar si existe o no intervención del Estado a través de la política social, sino que es preciso problematizar sus sentidos, considerando que son pasibles de contenidos y orientaciones diversas y también de distintos grados de protección social y que las orientaciones políticas no surgen solamente de lo que el gobierno realiza, sino también de lo que no hace y deja hacer, teniendo esto ciertas diferencias según el contexto social y económico. En esto, un papel clave tendrá la manera de configurar el problema a atender.

\section{La construcción del problema en torno a la pobreza, la informalidad y la falta de ingresos en Uruguay}

Antes de ingresar en la construcción del problema en relación a la pobreza, la informalidad y la falta de ingresos, interesa presentar tres asuntos que hacen a la orientación general del gobierno uruguayo en torno a la pandemia.

\section{El gobierno uruguayo ante la pandemia}

Pese al desarrollo del COVID-19, en países con los cuales Uruguay tiene amplia relación como España e Italia y luego en Argentinay Brasil, será recién el 13 de marzo, que el coronavirus 
2 Por otra parte, es cometido del Ministerio de Salud Pública: "Contribuir al mejoramiento de la salud e los habitantes de la República, elaborando las políticas de promoción de salud y prevención, normalizando $\mathrm{y}$ regulando el tratamiento y la rehabilitación de la enfermedad, bajo los principios rectores de universalidad, equidad, calidad, solidaridad, sustentabilidad y eficiencia” (MSP, 2020). ingresa a la sociedad uruguaya como realidad, pero también como tema para la coalición multicolor y en particular para el Presidente de la República y el Poder Ejecutivo. Una de las expresiones de esto, fue la falta de definición de las nuevas autoridades de la Administración Nacional de los Servicios de Salud del Estado (ASSE), principal prestador estatal de atención a la salud ${ }^{2}$. Será recién entre el 18 y el 25 de marzo que se designan las nuevas autoridades y por tanto pueden dejar sus cargos quienes estaban al frente de este organismo de enorme relevancia en la administración de la pandemia y sin posibilitar un adecuado tiempo de transición.

En cambio, las preocupaciones y ocupaciones estuvieron centradas en la elaboración de una Ley de Urgente Consideración (LUC), ampliamente rechazada por el Frente Amplio y un conjunto importante de organizaciones sociales. De acuerdo a Santiago Soto (2020) la Constitución del país, reserva un mecanismo especial de iniciativa legislativa para el Poder Ejecutivo, denominado 'urgente consideración', que tiene una característica distintiva y única y es el quedar aprobado al cumplirse un cierto plazo, sin que el Parlamento se expida en contra. Se trata de un plazo corto, apenas de 100 días para ser tratado por ambas cámaras. Dadas sus características e implicancias, y según Daniel Chasquetti (2020) entre la vuelta a la democracia en 1985 y a hasta 2019, fueron 13 los proyectos enviados a consideración de las cámaras alta y baja, con el rótulo de urgente consideración. De estos, 9 fueron aprobados y 4 rechazados.

El armado de esa ley -de 457 artículos en su primera versión y 501 en la definitiva- ocupó gran parte de la atención del nuevo gobierno previamente a asumir y cuando el coronavirus era una realidad presente en otros países y muy extendida en varios de ellos. El Presidente anuncia el 9 de marzo, que esa ley sería enviada al Parlamento el 16 de ese mes.

La pandemia solamente postergó, pero no modificó las urgencias y preocupaciones del nuevo gobierno. La declaración de la emergencia sanitaria fue acompañada de la idea de tratarse de una causa nacional. El Secretario de la Presidencia, Alvaro Delgado, en varias oportunidades indicó la respuesta a la pandemia como un tema ubicado por encima de cualquier diferencia o disputa, precisando del apoyo de los distintos sectores políticos. La imagen utilizada fue la del país entero, enfrentando la amenaza. Ante esta realidad, el 
16 de marzo, la Vice Presidenta Beatriz Argimón, comunica la postergación del envío de la LUC hasta nuevo aviso. Un mes después, el Presidente anuncia el ingreso al parlamento de esta ley, lo que finalmente ocurre el 23 de abril ${ }^{3}$, siendo aprobada en julio.

En segundolugar, aparece comoun problema sospechado por sus expresiones inmediatas. Integrantes del gobierno, de partidos de la coalición multicolor y el propio Presidente, expresan dudas sobre las cifras oficiales sobre informalidady pobreza. Este último, el 27 de marzo, en conferencia de prensa indicó que le llamaba la atención la cantidad de trabajadores informales, en relación a la información manejada por el Frente Amplio. Agregó que: "Es increíble como en 26 días han aparecido una enorme cantidad de trabajadores que según la información oficial con la que se contaba, no existía esa cifra en nuestro país"4. Ese mismo día, el subsecretario del Ministerio de Desarrollo Social, Armando Castaingdebat, manifestó sorpresa sobre la cantidad de trabajadores informales detectados por su cartera, con reclamos permanentes y crecientes de uruguayos que no tenían para comer, a pocos días de declarada la pandemia. Agregó que la respuesta a esta realidad se encuentra en los datos del Instituto Nacional de Estadística, y la cifra de trabajadores en negro:

Para mí, esta era una cifra nueva. Muchos actores dicen que no era nueva y que se conocía. Ya llegará el momento de tener una discusión seria, desde el sistema político, sobre por qué estaba pasando esto y cuál será la solución que vamos a desarrollar. Eso nos llevó a una situación de extrema vulnerabilidad socials.

En el mismo sentido, se ubicaron las declaraciones de Guido Manini Ríos, líder de Cabildo Abierto, socio relevante en el nuevo gobierno:

Descubrimos con cierta sorpresa que los números que manejábamos de gente en la informalidad y la pobreza eran muchísimos mayores que los números que se manejaban públicamente para el $1^{\circ}$ de marzo. Los números oficiales hablaban de una pobreza inferior al $8 \%$ que indudablemente no refleja la realidad que estamos descubriendo forzados por esta situación a veinte días de haber asumido. Nadie puede pensar que esta inmensa cantidad de uruguayos en estado de tanta fragilidad ocurrió en veinte días. Esta realidad era la que existía al $1^{\circ}$ de marzo $^{6}$.
${ }^{3}$ La Ley, integrada por 501, no es, de acuerdo a Daniel Chasquetti (2020) una ley ordinaria, sino un paquete de leyes que aborda más de 30 políticas públicas, en temas como seguridad, educación, empresas públicas, eficiencias del Estado, salud pública, vivienda, economía, relaciones laborales. Agrega que la mitad del articulado de la ley, modifica o suprime unas 60 leyes aprobadas durante los 15 años de gobiernos del Frente Amplio. Dados estos aspectos, el autor la ubica dentro de las llamadas 'leyes ómnibus', entendidas por los estudiosos de estos asuntos, como inconvenientes para la democracia al impedir un tratamiento parlamentario adecuado. Agrega que: “(..) se llegó a la conclusión de que las decisiones que se toman por esta vía restringen las posibilidades de un debate adecuado. Dado que una sola norma apunta a modificar el statu quo de varias políticas públicas a la vez, el análisis profundo y meditado por comisiones especializadas se vuelve improbable. Corrientemente, las leyes ómnibus viajan por las cámaras como paquetes que los legisladores nunca terminan de abrir. Desde luego, esta situación empeora si se agrega el mecanismo de la urgente consideración, pues a las dificultades estructurales para discutir cada tema se agrega el problema de los plazos legislativos. O sea, la combinación de unaleyómnibus con la urgente consideración vulnera las exigencias mínimas de calidad del Poder Legislativo" (Chasquetti, Daniel, 2020, p.1).

${ }^{4}$ Ver:

https://www.elobservador.com. uy/nota/el-cuestionamientode-lacalle-a-las-cifras-deinformalidad-y-las-dificultadespara-contemplar-a-estesector-2020327134843 
${ }^{5}$ Ver:

https://ladiaria.com.uy/ articulo/2020/3/datos-sobreinformalidad-generaronpolemica-entre-oficialismoy-oposicion-en-comision-delparlamento/

\section{${ }^{6}$ Ver:}

https://www.montevideo.com. uy/Noticias/Ernesto-Murro--Espeligroso-e-injusto-que-Lacalledude-de-cifras-de-informalidad-uc748325

\section{${ }^{7}$ Ver:}

https://www.lr21.com.uy/ politica/1427312-senadoragloria-rodriguez-acusa-alfrente-amplio-de-maquillarestadisticas-en-sus-gobiernos

\section{${ }^{8}$ Ver:}

https://www.presidencia. gub.uy/comunicacion/ comunicacionnoticias/medidascoronavirus-lunes-23

9 Estas elecciones en los 19 departamentos que componen el Uruguay debían realizarse el 10 de mayo de 2020 . Producto de la crisis instalada por el coronavirus, por unanimidad la Corte Electoral las pospuso para el 27 de setiembre (CORTE ELECTORAL, 2020).

${ }^{10}$ Ver:

https://www.teledoce.com/ telemundo/nacionales/lauraraffo-encabeza-el-proyectoelegi-ayudar-es-lo-que-estoyacostumbrada-a-hacer
Por su parte, Gloria Rodríguez, senadora por el Partido Nacional, acusó al Frente Amplio de adulterar las cifras estadísticas mientras fue gobierno. Afirmó que "Miles de pobres surgieron, ¿que? ¿de la nada? No señores, estaban. Simplemente maquillaban y maquillaban las estadísticas, y lo digo y lo reitero"7.

Esto supone que las dimensiones que el problema toma, son planteadas desde algunas autoridades de gobierno y/o de dirigentes que lo integran, con sospecha y lo hacen en aspectos que como se verá más adelante, tanto la CEPAL como la Universidad de la República, plantean como centrales en las consecuencias presentes y futuras de la crisis.

Finalmente, otro eje en las orientaciones generales, es la idea que la gestión de la crisis, no es de carácter político. Ante la consulta sobre la eventualidad del aislamiento total, el Presidente responde que: "Nosotros no estamos haciendo política. No vamos a hacer política. Nosotros estamos gobernando"s. Esta idea fue también sostenida por Laura Raffo, candidata a la Intendencia de Montevideo $^{9}$ por la coalición multicolor en las elecciones departamentales, quien a partir de su iniciativa denominada Elegí Ayudar, afirmó que "No es momento de embanderarse en términos políticos"1.

\section{El gobierno uruguayo ante la pobreza, informalidad y falta de ingresos}

El COVID-19, desde el 13 de marzo, se configura como problema que permite, además, una amplia presencia mediática en los medios masivos de comunicación. Entre los 23 días que van del 13 de marzo al viernes 4 de abril (fecha clave en el país por dar comienzo al fin de semana previo a la Semana de Turismo o Santa) se desarrollan 19 conferencias de prensa. Al primero de mayo, son 50 días, siendo 34 las conferencias de prensa. En muchas ocasiones suponen la presencia del Presidente Lacalle, que siempre con más de una persona integrante del Poder Ejecutivo, ingresan en los hogares en el horario central de los informativos e instalan una imagen de un gobierno actuando y haciéndose cargo de la situación. A esto es preciso sumar, la reproducción de estas conferencias durante otros informativos y programas, más declaraciones de Ministros y Ministras y comunicados del Servicio Nacional de Emergencias (SINAE). 
ElCOVID-19, es considerado un problema por el gobierno, pero se entiende que desde cuatro aspectos centrales, que resultan problemáticos para la pobreza, la falta de ingresos y la informalidad.

En primer lugar, se configura básicamente como un problema de salud y económico y no ingresan (o lo hacen de manera reducida) en su consideración dimensiones políticas, ambientales y sociales. Estos últimas, vinculadas a como las distintas personas, las familias, los barrios, llegan al aislamiento físico y viven en este singular contexto y sus preocupaciones futuras, emergen débilmente en los relatos y son pocos los asuntos entendidos como problemáticos.

Luego de unos días de avanzada la emergencia, aparecen muy tímidamente en los discursos, complejidades asociadas a la violencia de género y a situaciones de ansiedad o depresión provocadas por el aislamiento. En relación al primero de estos asuntos, los anuncios públicos se dan a fines de marzo y son acelerados a partir de la declaración del Presidente de los femicidios como un 'efecto colateral' provocado por el aislamiento ${ }^{11}$. El tema fue parte solamente de una de las conferencias de prensa de marzo, cuando Mónica Bottero, directora del Instituto de las Mujeres (INMUJERES), anunció diversas medidas al respecto. El segundo asunto entra en agenda en los primeros días de abril. El Ministerio de Salud Pública, el 16 de ese mes, anuncia una línea de atención telefónica, gratuita y confidencial para quienes sientan estrés, ansiedad, angustia y precien apoyo (MSP, 2020). Además, en el informativo central, aparecen teléfonos para llamar para ayuda psicológica por ambas realidades mencionadas.

Dentro de la dimensión social, aparecen débilmente los impactos en el trabajo informal, los ingresos y la pobreza. Esta baja consideración de los aspectos sociales de la pandemia es también observable en la comunicación del Presidente del 17 de abril, cuando anuncia que el país se encamina a iniciar una etapa distinta, la que denomina 'nueva normalidad' y que supone pasar del aislamiento al distanciamiento social ${ }^{12}$. Se trata de un escenario que tiene el asesoramiento de una Comisión de Científicos, donde no hay ninguna persona fuera de las áreas económicas y sanitarias. Integran ese equipo un economista (Isaac Alfie, director de la Oficina de Planeamiento y Presupuesto), un matemático (Fernando Paganini), un bioquímico (Rafael Radi) y un gastroenterólogo (Henry Cohen).

\footnotetext{
${ }^{11}$ Ver:

https://www.montevideo. com.uy/Noticias/Criticasa-Lacalle-tras-decir-queultimos-femicidios-son-efectocolateral-de-cuarentenauc747969
}

${ }^{12}$ Ver:

https://www.presidencia. gub.uy/comunicacion/ comunicacionnoticias/lacallepou-conferencia-nuevanormalidad 
Además de baja consideración de los aspectos sociales de la pandemia, esta aparece como una realidad uniforme para todos y todas. El único asunto claro de distinción es la edad, identificando a las personas mayores de 65 años, como parte de la población de riesgo. Pero incluso dentro de ese universo, la realidad, aparece y parece igual para todas las personas.

Esta mirada a la pandemia como una realidad existente más allá de las diversidades, es fortalecida por la intensa convocatoria a pensar el país en su conjunto, "De esta salimos todos juntos"; "Este partido lo ganamos entre todos. Gracias por cuidarse. Gracias por cuidarnos"; "Juntos podemos", hacen parte de los ejes centrales del discurso público promovido por el gobierno.

Hay un cierto reconocimiento de dificultades, una referencia a sectores que lo 'están pasando peor', pero esto no toman centralidad en el discurso. No surgen en este las dificultades para atender las necesidades propias y de las familias de mucha gente. No hay una problematización sobre las condiciones habitacionales, donde muchas veces, no es posible realizar las indicaciones sanitarias y de aislamiento físico, el tele trabajo y continuar trayectos educativos. Tampoco lo hay de las mayores exigencias que esto supone para las familias y en particular, para las mujeres, ni las diferencias agudizadas entre los sistemas educativos públicos y privados, entre otros aspectos.

Todo esto lleva a la ausencia de discurso en relación a las desiguales formas de transitar el coronavirus, que no son otra cosa que expresión de las desigualdades con las que el país llega a esta realidad, pero también de las que pueden agudizarse y desarrollarse según lo que se haga durante la crisis.

Dentro de esa realidad desigual, interesa poner foco en los impactos en el trabajo y en el ingreso. A partir del COVID-19, en muy poco tiempo, muchas personas pierden la posibilidad de desarrollar sus trabajos de manera informal, otras acceden a protección a través del trabajo formal, pero con reducción de su salario. Se trata de muchas personas cuyos ingresos pasan a estar afectados y sus vidas, más marcadas aún por la inestabilidad e inseguridad. No saben como van a vivir hoy y tampoco como lo harán más adelante. El trabajo y los ingresos, tienen centralidad en la vida de las personas con altos impactos en el conjunto de la sociedad, pero además son dimensiones relevantes en tanto existe 
margen de acción rápida de parte del gobierno.

En tercer lugar, el COVID-19 se configura como un problema que, en la residual consideración de la dimensión social, lo hace, además, en versiones mínimas, básicamente centradas en comer y mantenerse vivas las personas más afectadas. Como fuera mencionado, no tiene relevancia en el discurso de gobierno, la necesidad de garantizar ingresos. Esto llevará a que, aunque ambas presentes, sean las canastas (directamente o a partir de donaciones privadas), y no las transferencias monetarias, lo que tenga centralidad en lo destacada por el gobierno como respuesta y así, confirmando y contribuyendo a la delimitación del problema.

Finalmente, la pandemia es considerada un problema profundo pero breve. Este ha sido uno de los ejes centrales del discurso de la Ministra de Economía, Azucena Arbeleche, insistiendo en el impacto significativo, pero transitorio ${ }^{13}$. Luego de fuertes exhortaciones a sostener el aislamiento, realizadas por el gobierno, en los días previos al inicio de la Semana de Turismo o Santa, el miércoles de esa semana (8 de abril), el Presidente Lacalle declara la necesidad de poner foco en el 'día después' y como fuera mencionado, rápidamente instala la idea de orientar el país a la 'nueva normalidad'.

Esta manera de configurar el problema, tendrá fuerte incidencia en las respuestas que el gobierno ha venido llevando adelante, que básicamente han supuesto la duplicación del monto percibido a través de las transferencias monetarias Tarjeta Uruguay Social (TUS) y Asignaciones Familiares (AFAM). Estas fueron anunciadas por un único mes y con el pago repartido en dos meses (abril y mayo). Este procedimiento se repitió tres veces más, esto es, cada vez fue anunciada una nueva duplicación y su pago dividido en dos instancias.

El eje central de la respuesta ha sido la entrega de canastas, a través de dos modalidades (productos en un caso y dinero en otro, mediante una aplicación para gastos en alimentos y productos de higiene) y con un valor de $\$ U$ 1200 (USD 27 aproximadamente). Estas están excluidas para quienes reciban transferencias y fueron anunciadas en marzo por un único mes, definiendo luego su reiteración. El MIDES también realiza una apuesta a las donaciones, creando un portal de para las mismas y una mesa para su gestión. Estas y el formulario para el acceso a las canastas, ocupan buena parte de la página web del organismo. Las
13 Ver: https://www.subrayado. com.uy/ministra-economiaasegura-que-el-impactoeconomico-sera-significativopero-transitorio-n614489 
respuestas son destacadas por el gobierno en su aspecto cuantitativo, reiterando una y otra vez 'la cantidad' otorgada, pero sin discutir que son de muy baja materialidad y, además puntuales, no permitiendo ni mínimamente reducir la inseguridad generada por la imposibilidad de trabajar y/o haber visto reducidos los ingresos.

A lo anterior es preciso sumar distintas expresiones de donaciones de empresas privadas, fundamentalmente, de canastas, que cuentan con la participación de la esposa del Presidente, Lorena Ponce de León en un caso y en otro, de la candidata para las elecciones departamentales Laura Raffo. Finalmente, ha habido un gran desarrollo de ollas populares, valoradas por el Ministro de Desarrollo Social, como expresión de la solidaridad de la sociedad uruguaya.

Problema y respuesta llevarán a un desajuste muy importante con la realidad. La CEPAL ha elaborado informes sobre el COVID-19, indicando que la pandemia tendrá repercusiones negativas en la salud y la educación, el empleo y la pobreza. Afectará el número de empleos (aumentando el desempleo y el subempleo y de manera desproporcionada en los pobres y vulnerables) y su calidad (con reducción de salarios y menor acceso a la protección social) y a los grupos más vulnerables, como las y los trabajadores informales. Entiende que es posible que este tipo de empleo aumente como estrategia de supervivencia, así como el trabajo de niños, niñas y adolescentes. Esta situación supondrá un crecimiento de la pobreza y la desigualdad. Agrega que los efectos sobre el PIB y el empleo, varían entre los países y por tanto también, sus consecuencias. En función de esto, presenta tres escenarios de evolución de la pobreza y la extrema pobreza en 17 países de la región. La pobreza aumentaría $4.4 \%$ en el escenario medio, 3.4 en el bajo y 5.5 en el peor de los casos (CEPAL, $2020 \mathrm{a}$; 2020b).

A partir de este diagnóstico realiza recomendaciones de política, orientadas a evitar otra década como la de los 80 . Por un lado, destaca la necesidad de: “... respuestas rápidas y contundentes de manera de reducir los impactos. Aunque no se sabe cuánto durará la crisis ni la forma que podría tener la recuperación, cuanto más rápida y contundente sea la respuesta, menores serán los efectos negativos" (CEPAL, 2020 a, p. 1). Esto supone un activo papel del Estado, que entiende el organismo debe articular acciones de corto y mediano y largo plazo. En el primer grupo propone que los gobiernos 
garanticen transferencias monetarias temporales, con una duración mínima de tres meses, siendo deseables seis meses o un año, mejorando así la protección a la población. Entiende que:

(...) asegurar los ingresos y el consumo en los hogares, contrarresta la pérdida de fuentes de ingresos laborales y sostiene la demanda, al tiempo que facilita el acceso a la salud. Las acciones clave son el establecimiento de una garantía universal de ingresos, especialmente para los trabajadores informales y precarios, así como el acceso universal a las pruebas y a la atención médica a todos quienes lo necesiten, a los servicios básicos y a la vivienda, a la alimentación adecuada y a la educación en el caso de niños, niñas, adolescentes y personas jóvenes (CEPAL, 2020 b, p. 19).

En el mediano y largo plazo, indica CEPAL (2020 b) que será crucial consolidar sistemas de protección social universales, redistributivos y solidarios y con un enfoque de derechos.

Para el caso uruguayo, Brumy da Rosa (2020) del Instituto de Economía de la Universidad de la República, a partir de cuantificar la contracción en los niveles de empleo e ingresos, procuran visualizar los impactos sobre la pobreza ${ }^{14}$ en abril de 2020, más específicamente se orientan a comprender la cantidad de personas que pasan a estar bajo la línea de pobreza a partir de la pandemia y la capacidad de las medidas implementadas para neutralizar sus efectos negativos. En base a los datos de la Encuesta Continua de Hogares, simulan el envío a seguro de paro de unos 140 mil trabajadores y trabajadoras formales; la pérdida de empleo e ingresos para los trabajadores y trabajadoras informales y cuentapropistas en función de la contracción prevista de la economía y las principales medidas desplegadas por el gobierno.

Parten de considerar que más allá de la dimensión estrictamente sanitaria de la crisis, habrá una contracción económica de más larga duración, que recaerá en mayor medida, sobre las personas de bajos e inestables ingresos y de la población vinculada al empleo informal y las conclusiones a las que arriban son tres (Brum y da Rosa, 2020).

Entienden que el número de hogares y personas por debajo de la línea de pobreza se incrementa rápidamente. Considerando una caída de 3,5\% del Producto Interno Bruto (PIB), la incidencia de la pobreza tras la acción de las nuevas
${ }^{14}$ En la definición de pobreza, utilizan el enfoque monetario, que es el utilizado por el Instituto Nacional de Estadísticas y por tanto un hogar es considerado pobre, si el ingreso corriente con valor locativo del hogar es menor al de la línea de pobreza determinada para ese hogar, que tiene en cuenta la canasta básica de alimentos, la no alimentaria y el número de integrantes del hogar. Son pobres las personas que pertenecen a un hogar pobre. La línea de pobreza depende, de la ubicación geográfica del hogar y de su número de integrantes. A modo de ejemplo, la línea de pobreza para un hogar de tres integrantes en Montevideo, actualizado a marzo de 2020, es de $\$ 38.933$ (Brum y Da Rosa, 2020). 
políticas desplegadas trepa al 11,6\% (incremento de 3,1 puntos porcentuales) y se ubica entre $11,2 \%$ y $12,1 \%$ dependiendo de distintos escenarios. Esto supone que entre $94.000 \mathrm{y}$ 127.000 personas pasan a ser pobres. En segundo lugar, consideran que las medidas implementadas por el gobierno, si bien moderan levemente el aumento de la pobreza, son insuficientes para contenerlo. En promedio, las medidas representan el $4 \%$ de los ingresos de los hogares destinatarios de las nuevas políticas (Brum y da Rosa, 2020).

Finalmente, en opinión de los autores, el aumento en la pobreza es en gran medida mitigable y su incremento de corto plazo puede neutralizarse por medio de transferencias monetarias. Agregan que las cifras que esto supone, sugieren órdenes de magnitud que indican que una respuesta más próxima a los desafíos impuestos por la crisis está dentro del alcance de las políticas públicas (Brum y da Rosa, 2020).

\section{Síntesis y conclusiones}

En Uruguay, existe coincidencia entre la declaración de emergencia por el COVID-19 y el nuevo gobierno, que pone fin a 15 años de gobiernos progresistas a cargo del Frente Amplio. Esa declaración se realiza 13 días después de asumir el Presidente Lacalle Pou y a partir de los primeros cuatro casos positivos. La pandemia no fue parte de las preocupaciones de las nuevas autoridades, ni en los primeros días de marzo, ni de forma previa a ese momento. En cambio, estas aparecen centralmente en torno a la Ley de Urgente Consideración (LUC) cuya primera versión se da a conocer a fines de enero, ocupando parte de la atención durante febrero y los primeros días de gobierno.

La gestión de la pandemia por parte del nuevo gobierno, asume una dimensión altamente mediática, con un amplio desarrollo de conferencias de prensa, declaraciones, entrevistas y comunicados, que instalan la imagen de un 'gobierno que se hace cargo' y de cara a la ciudadanía.

Este artículo puso en foco en analizar la manera en que se configura el problema de la pandemia en el Uruguay, específicamente en relación a la pobreza, informalidad y falta de ingresos. Se considera que esto tiene relevancia por dos motivos fundamentales. En primer lugar, dado que impactará en las orientaciones de respuesta que se promuevan y esto supone tanto lo que el Estado realiza y la manera en que 
lo hace, como aquello que opta por no hacer y dejar hacer a otros. Luego, porque se considera que esta gestión, en particular la construcción del problema y su respuesta, no es externa o ajena a la mirada de la realidad que tiene el nuevo gobierno y, al contrario, las decisiones tomadas, ilustran las orientaciones que procurarán promoverse los próximos años. Esto no supone que necesariamente vayan a ocurrir, en tanto, la vida social y política no se reduce a la acción de gobierno, pero claramente expresan a este.

Al analizar el contenido de lo anunciado, se observa una configuración del problema menos expandida y, al contrario, bastante restringida, con impactos relevantes en las respuestas implementadas y por tanto en la vida de las personas.

Aún y a pesar de las dudas expresadas por integrantes del gobierno y entre ellos, el propio Presidente Lacalle, sobre las cifras sobre informalidad y pobreza, la pandemia aparece como un problema básicamente sanitario y económico. Rápidamente estabilizada la primera dimensión, toma centralidad la preocupación por la reactivación económica, que parece ser la apuesta central a la atención de la pobreza, los bajos o nulos ingresos y la informalidad. Ante una consulta sobre impuestos a los sectores de altos ingresos del sector privado para sumar al Fondo Coronavirus ${ }^{15}$, el Presidente respondió, que no sería gravado el capital, en tanto eso supone amputar las posibilidades de los que harán fuerza en la salida de la crisis ${ }^{16}$. Esto se articula con la idea de una crisis fuerte pero breve, potenciándose mutuamente. Parecerían no ser necesarias medidas de magnitud y sostenidas en el tiempo, dado que el país se encamina a salir de la crisis.

Hay un reconocimiento de sectores que lo están pasando peor y allí la preocupación se coloca en la alimentación y entonces garantizar un plato de comida, pasa a tener centralidad. Esto lleva a que sean las canastas -tanto las gestionadas directamente por el gobierno, como por acciones voluntarias de empresarios que donan al MIDES- sean el eje central de las respuestas. Es evidente que el que las personas estén vivas es el primer asunto, pero la vida debiera ser garantizada más allá de esta expresión mínima. A esto se suman las ollas populares, cuyo desarrollo es amplificado por los medios masivos de comunicación, sin ser nunca -en tanto no siguen las indicaciones de aislamiento físico-desalentadas por el gobierno y al contrario valoradas como expresión de

\footnotetext{
${ }^{15}$ Se trata de una herramienta diseñada por el gobierno por dos meses, para cubrir las necesidades sociales y sanitarias, generadas por el COVID - 19. Se integra por utilidades de las empresas públicas y bancos estatales y de préstamos de los organismos multilaterales de crédito. A esto se agrega el aporte de los salarios de unos 15.000 funcionarios públicos con sueldo líquido por encima de $\$ \mathrm{U}$ 80.000 y los aportes salariales de las personas con cargos políticos electos y designados. Ver: https://www.presidencia.gub. uy/comunicacion/comunicacionnoticias/fondo-coronavirus-conferencia

${ }^{16}$ Ver:

https://www.presidencia. gub.uy/comunicacion / comunicacionnoticias/lacallepou-clases-coronavirus
} 
la solidaridad. Esta valoración, jamás se cruza con el drama que expresan por la enorme cantidad de personas que, para alimentarse, precisan recurrir a estos espacios.

Las serias dificultades en los ingresos, para un número muy importante de personas, aparecen bajamente en los discursos de gobierno y cuando lo hacen, es básicamente para dar cuenta de la 'herencia recibida' pero no toman ninguna relevancia en las respuestas construidas. La llegada a la pandemia, el tránsito por ella y la realidad a su salida, no son tensionadas y problematizadas desde la desigualdad, que no parece ser una preocupación del nuevo gobierno. Esto hace que las transferencias de ingresos no tengan centralidad en la respuesta del gobierno uruguayo, a distancia de recomendaciones como las realizadas por la CEPAL y la Universidad de la República.

El espacio del Estado en la protección social, es un asunto de disputa social y política. Aunque de tensión en torno a la política asistencial, esto varía en función de los contextos económicos y sociales y en particular, la realidad del trabajo. Lo que este episodio muestra es que aún en un escenario de crisis, que sin duda habilita y otorga legitimidad a una firme acción del Estado, el gobierno uruguayo, elige no hacerlo. No forma parte de la configuración del problema realizada, la responsabilidad pública en atender las consecuencias de la crisis. Desarrolla algunas acciones de muy corta duración y bajo impacto en relación a la situación del país y en cambio valora y promueve las expresiones de la solidaridad y parece confiar en el mercado y de esta manera privatiza la crisis y sus respuestas. Esto lleva a recordar la orientación del bienestar de los años 90 y por tanto también sus consecuencias, que supusieron mayor pobreza, informalidad e intensificación de la desigualdad social.

\section{Referencias bibliográficas}

ArIAs, Ana (2012). Pobres y modelos de intervención. Aportes para la superación del modelo de asistencia y promoción. Buenos Aires: Espacio Editorial.

Brum, Matías y Da Rosa, Mauricio (2020). Estimaciones del efecto de corto plazo de la covid - 19 en la pobreza en Uruguay. Serie de comunicaciones del Instituto de Economía Aportes y análisis en tiempos de coronavirus. 
Recuperado el 15 de mayo 2020, de http://www.iecon. ccee.edu.uy/

Cepal (2020 a). América Latina y el Caribe ante la pandemia del COVID - 19. Informe especial COVID - 19, $\mathrm{N}^{\circ} 3$. Recuperado el 14 de mayo, de 2020 de https://www.cepal. org/es/publicaciones/45527-desafio-social-tiemposcovid-19

Cepal (2020 b). El desafío social en tiempos de COVID 19. Informe especial COVID - 19, $\mathrm{N}^{\circ} 3$. Recuperado el 14 de mayo, de 2020 de https:/www.cepal.org/es/ publicaciones/45527-desafio-social-tiempos-covid-19

Corte Electoral (2019). Elecciones nacionales 2019. Recuperado el 20 de abril de 2020 , de www.corteelectoral. gub.uy

Crespo, Eduardo y Serrano, Amparo (2013). Las paradojas de las políticas de empleo europeas: de la justicia a la terapia. En Universitas Psycologica, Bogotá, volumen 12, $\mathrm{N}^{\circ}$ 4, pp. 1111-1124. Recuperado el 29 de marzo de 2019, de https:// dialnet.unirioja.es/servlet/articulo? codigo $=4972475$

Chasquetti, Daniel (2020). Los proyectos de ley de urgente consideración en Uruguay. En la diaria. Recuperado el 15 de marzo de 2020, de www.ladiaria.com.uy/opinion/ articulo/2020/1/los-proyectos-de-ley-de-urgenteconsideracion-en-uruguay/

Danani, Claudia (2008). América Latina luego del mito del progreso neoliberal: las políticas sociales y el problema de la desigualdad. En Revista Ciencias Sociais Unisinos, San Leopoldo, volumen 44, $\mathrm{N}^{\circ}$ oo1, volumen, pp. 39-48. Recuperado el 28 de agosto de 2018, de http://www. revistas.unisinos.br/index.php/ciencias_sociais/article/ view/5264

DANANI, Claudia (2009). La gestión de la política social: un intento de aportar a su problematización. En Chiara, M.y Di Virgilio, M. (org.) Gestión de la política social. Conceptosy herramientas (pp. 25-51). Buenos Aires: UNGS - Prometeo Libros.

Esping-Andersen, Gosta (2000). Fundamentos sociales de las economías postindustriales. Barcelona: Editorial Ariel.

Grassi, Estela (2006). Políticas y problemas sociales en la sociedad neoliberal. La otra década infame [I]. Buenos Aires: Espacio Editorial.

Grassi, Estela (2008). La política social, las necesidades sociales y el principio de la igualdad: reflexiones para un 
debate "post-neoliberal". En Ponce, J. (editor) Es posible pensar una nueva politica social para América Latina. (pp. 2968). Quito: FLACSO.

Grassi, Estela (2013). El sujeto de la política social. Obstáculos persistentes y condiciones necesarias para el ejercicio de los derechos. En Revista Ser Social, Brasilia, vol. 15, $\mathrm{N}^{\circ}$ 33, pp. 280-300. Recuperado en 15 de octubre de 2015, de https://periodicos.unb.br/index.php/SER_Social/ article/view/13048

Hopp, Malena y LijTerman, Eliana (2018). Trabajo, políticas sociales y sujetos 'merecedores' de la asistencia: acuerdos y debates en el nuevo contexto neoliberal en Argentina. En Revista Perspectiva de Politicas Públicas, Buenos Aires, vol. 8, $\mathrm{N}^{\circ} 15$, pp. 139-171. Recuperado el 26 de mayo de 2019, de http://revistas.unla.edu.ar/perspectivas/article/ view/2084

Ministerio De Salud Pública (MSP). Línea de apoyo emocional. Recuperado el 2 de mayo de 2020, de www. gub.uy/ministerio-salud-publica

Pereira, Potyara (2008). Politica Social, temas \& questoes. San Pablo: Cortez Editora.

Soldano, Daniela y Andrenacci, Luciano (2005). Aproximación a las teorías de la política social a partir del caso argentino. En Andrenacci, L. (comp.) Problemas de política social en la Argentina contemporánea (pp. 17-79). Buenos Aires: UNGS - Prometeo Libros.

Sото, Santiago (2020). Urgencias, coaliciones y pandemias. En la diaria. Recuperado el 25 de abril de 2020, de https:// ladiaria.com.uy/opinion/articulo/2020/4/urgenciascoaliciones-y-pandemias-visteme-despacio-que-estoyapurado/

Fecha de recepción: 19 de mayo de 2020 Fecha de aceptación: 11 de noviembre de 2020

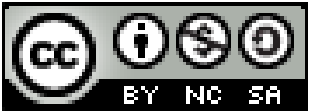


MILLCAYAC - Revista Digital de Ciencias Sociales / Vol. VIII / N 14 / marzo 2021 - agosto 2021. 36 ISSN 2362-616x. (pp. 13-36). SIPUC. FCPyS. UNCuyo. Mendoza 